\title{
Exégesis filosófica en las interpretaciones de Abraham ibn Ezrá al libro de $J o b$
}

\author{
Mariano GómEz ARANDA \\ CSIC, Madrid
}

\section{INTRODUCCIÓN}

En la Edad Media, el impulso que los musulmanes dieron al pensamiento filosófico influyó en la mentalidad de los exegetas bíblicos judíos que encontraron en la filosofía un camino para la interpretación racional de la Biblia. Libros, capítulos y pasajes bíblicos, cuya interpretación hasta ese momento no tenía más apoyo que la propia tradición judía, cobraron a partir de entonces un nuevo sentido a la luz del pensamiento racional-filosófico ${ }^{1}$.

Abraham ibn Ezrá (1089-1160) fue uno de los comentaristas bíblicos que más utilizó las teorías filosóficas de su tiempo, especialmente aquellas de tendencia neoplatónica, para sus interpretaciones bíblicas. En este artículo analizaré cómo utiliza esas teorías para interpretar el texto del libro de Job y encontrar así una justificación del asunto que tantos problemas de interpretación ha suscitado a lo largo de la historia de la exégesis: el justo que sufre desgracias sin razón aparente ${ }^{2}$.

\footnotetext{
1 El estudio más completo sobre las interpretaciones filosóficas en la exégesis judía medieval es el de M. R. HAyoun, L'exégèse philosophique dans le judaïsme médiéval (Tübingen 1992). El trabajo general más reciente sobre este tema es el de S. Klein-Braslavy, "The Philosophical Exegesis», en M. SÆBø (ed.), Hebrew Bible/Old Testament. The History of Its Interpretation, Vol. I: From the Beginnings to the Middle Ages (Until 1300), Part 2: The Middle Ages (Göttingen 2000) págs. 302-320.

2 Para el texto del comentario de Ibn Ezrá a Job me he basado en los manuscritos que estoy utilizando para preparar la edición crítica.
} 


\section{EL ORIGEN DEL MAL}

Abraham ibn Ezrá suele comenzar sus comentarios bíblicos con introducciones en las que hace un resumen de los contenidos y del estilo del libro que se propone comentar y, en ocasiones, también trata de justificar sus métodos exégeticos y sus opiniones ${ }^{3}$. En la introducción de su comentario a Job, Ibn Ezrá analiza el asunto central de este libro bíblico: el origen del mal y las desgracias que le suceden al que se ha comportado de manera justa y honrada, que ha seguido fielmente la ley de Dios y no ha cometido pecados.

Ibn Ezrá comienza su introducción con unas observaciones de carácter filosófico que requieren un análisis minucioso y exhaustivo. Dice así:

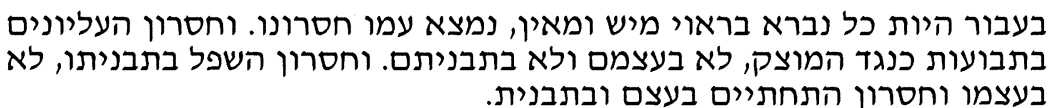

En este fragmento Ibn Ezrá comienza explicando la creación a partir de dos principios, 'existencia' (יש) y 'no existencia' (אין).

3 La existencia de introducciones a los comentarios bíblicos en las que se resume el contenido del libro y se hacen observaciones sobre su estilo, tal como aparecen en los comentarios actuales, no era habitual entre los exegetas medievales que, como en el caso de Rasí, solían comenzar sus explicaciones por el primer versículo del primer capítulo del libro que se proponían comentar sin introducirlo de ninguna manera. El primero que se plantea la necesidad de este tipo de introducciones es Saadiá Gaón y, aunque tuvo una enorme influencia en los exegetas de la España medieval, no fue precisamente esta característica una de las que más influyeron. Sobre las introducciones de Saadiá Gaón, véase J. J. RIVLIN, «R. Saadiah Gaon's Prefaces to his Commentaries as an Introduction to the Bible» [en hebreo], en J. L. Fishman (ed.), Rab Se'adiá Gaón. Cóbes ToraníMadda'í (Jerusalem 1943) págs. 382-427; E. I. J. RosenTHAL, «Saadya Gaon: An Appreciation of his Biblical Exegesis», Bulletin of the John Rylands Library 27 (1942) págs. 168-178; y H. BEN-SHAMmAI, «Rabbi Saadiah Gaon's Preface to Isaiah, an Introduction to the Later Prophets» [en hebreo], Tarbiz 60 (1991) págs. 371-404. La introducción de Ibn Ezrá a su comentario al Pentateuco es una de las más importantes porque en ella expone los diversos métodos de interpretación bíblica que existían hasta su tiempo y defiende el que considera más adecuado; la han estudiado W. BACHER, Abraham Ibn Esra's Einleitung zu seinem PentateuchCommentar (Wien 1876), y F. VARO, «La hermenéutica bíblica en el prólogo al Comentario a la Torah de Abraham Ibn Ezra», en Biblia, Exégesis y Cultura. Estudios en honor del Prof. José María Casciaro, bajo la dirección de G. ARANDA, C. BASEVI y J. CHAPA (Pamplona 1994) págs. 463-473. Sobre su introducción al comentario a Salmos, véase U. Simon, Four Approaches to the Book of Psalms. From Saadia Gaon to Abraham Ibn Ezra (Albany 1991) págs. 145-295, 308-323 y 330-333. 
Rechaza, pues, el concepto de creación ex nihilo y, por el contrario, defiende la creación a partir de algo ya existente ${ }^{4}$. La no existencia es definida en este contexto como la carencia o privación (חסרון) de algo. El significado de la primera frase es el siguiente: «puesto que todo ser ha sido creado adecuadamente a partir de la existencia y de la no existencia, lleva consigo su propia carencia». La palabra חסרון, entendida aquí en el sentido de "carencia' o 'privación', tiene para Ibn Ezrá además otro sentido. En su comentario a $E c l 11,15$, Ibn Ezrá explica que su significado quiere decir que «el que nace bajo una disposición incompleta o imperfecta de los astros en el firmamento, no tiene poder para colmar sus deseos» ${ }^{5}$. Se refiere a una disposición de los astros que determina privación o carencia de algo en los seres humanos y así aquí está haciendo alusión a una imperfección natural de todos los seres que están bajo la influencia de los astros. De la misma manera, en el fragmento de su introducción al comentario a $J o b$, Ibn Ezrá quiere decir que todos los seres creados son imperfectos por el mero hecho de haber sido formados a la vez a partir de algo existente y no existente.

Después de esta afirmación, nuestro autor especifica en qué parte radica la imperfección de cada uno de los tipos de seres que existen. En primer lugar menciona los עליונים que, en otras obras de Ibn Ezrá, son los seres que habitan en el mundo superior y que engloban tanto a los ángeles como a los astros. La imperfección de estos seres deriva de «sus movimientos frente a la tierra ${ }^{6}$ » y además añade que no está ni en su esencia (עצמם) ni en su forma (תבניתם), es decir, que ambas son perfectas.

${ }^{4}$ Ibn Ezrá expresa esta misma idea en su comentario largo a Gén 1,1 donde explica que el verbo ברא 'crear' significa 'cortar' y 'poner límites a lo que se ha cortado'; cfr. A. WeIZER (ed.), Peruše ha-Torá le-Rabbenu Abraham ibn 'Ezrá (Jerusalem 1976) vol. I (en adelante Com. Gén.) pág. 12. Una explicación similar aparece en sus comentarios a Is 40,28 e Is 42,5. En su comentario a Is 65,18 , dice Ibn Ezrá que ברא tiene el sentido de 'renovar'; cfr. M. FrIEDLÄNDER (ed.), The Commentary of Ibn Ezra on Isaiah (London 1873) págs. 67, 71 y $112(179,188$ y 297-298 de la traducción). Sobre las explicaciones de Ibn Ezrá al término hebreo ברא, cfr. Y. CoHEN, Hagutó ha-Filosofit sel Rabbí Abraham ibn 'Ezrá (Jerusalem 1996, en adelante COHEN) págs. 107-110.

5 M. GÓmez ARANDA (ed.), El comentario de Abraham Ibn Ezra al libro del Eclesiastés (Madrid 1994; en adelante Com. Ecl.) págs. 18*, 29.

${ }^{6}$ Sobre la palabra מוצק con el significado de 'tierra', cfr. M. GóMEz ARANDA, «Aspectos científicos en el comentario de Abraham ibn Ezra al libro de Job», Henoch 23 (2001) págs. 81-96: 88-90. 
En su comentario largo a Éx 3,15, al referirse a los astros dice Ibn Ezrá lo siguiente: «son permanentes en su esencia, ni se les puede añadir, ni se les puede quitar, sus movimientos son invariables, ni aumentan ni disminuyen, ni suben, ni bajan» ${ }^{7}$. ¿Por qué dice Ibn Ezrá en su introducción al comentario a $J o b$ que su imperfección está en sus movimientos frente a la tierra? Lo que quiere decir es que, aunque sus movimientos son eternos, invariables y constantes, desde el punto de vista de un observador terrestre parece que cambian y son diferentes, es decir, que la supuesta imperfección de estos seres es sólo aparente pues depende de nuestro punto de vista, pero no es real; los seres superiores son perfectos porque su propia constitución es perfecta, pues tanto su esencia como su forma así lo son.

Después Ibn Ezrá especifica que la imperfección de השפל «está en su forma, no en su esencia» y a continuación se refiere a la imperfección de התחתיים que está «en su esencia y en su forma». ¿A qué alude Ibn Ezrá en este pasaje con los términos השפל y (התחתיים?

Ibn Ezrá utiliza la palabra השפל en varios comentarios para indicar el mundo sublunar, la tierra y todos los seres que habitan en ella, aunque en general aparece como העולם השפל. Así, por ejemplo, en el segundo comentario a Gén 2,1 Ibn Ezrá contrapone השפל y para expresar, por una parte, el mundo superior de los ángeles y los astros y, por otra, el mundo terrenal ${ }^{8}$. En su comentario largo a $E$ x 3,15 Ibn Ezrá habla de la existencia de tres mundos: el mundo superior (העולם העליון), que es el mundo de los ángeles, el mundo intermedio (העולם האמצעי), donde se encuentran los astros, y el mundo inferior (העולם השפל (המלם). Refiriéndose a este último explica que engloba a los metales, las plantas y los seres vivos y añade que el ser humano ocupa el nivel superior del mundo inferior ${ }^{9}$.

Respecto a la palabra התחתיים encontramos un caso similar en su comentario corto a Éx 23,20. Aquí explica que el ser humano

\footnotetext{
7 A. Weizer (ed.), Perušé ha-Torá, vol. II (en adelante Com. Éx.) pág. 34.

8 Com. Gén. pág. 165. Véanse también sus comentarios a Gén 1,14, Sal 148 y Dan 10,21. Sobre la división del cosmos en dos mundos en el pensamiento de Ibn Ezrá, véase S. SElA, Astrology and Biblical Exegesis in Abraham Ibn Ezra's Thought [en hebreo] (Ramat Gan 1999) págs. 14 y 96.

9 Com. Éx. pág. 34.
} 
ejerce control y dominio sobre los seres inferiores (התחתיים) y suponemos que está aludiendo a los demás seres del mundo terrenal ${ }^{10}$.

En conclusión, Ibn Ezrá en el pasaje de la introducción a su comentario a $J o b$ utiliza השפל para referirse al ser humano y התחתיים para indicar los demás seres terrenales ${ }^{11}$.

Al explicar en qué parte de ambos seres se encuentra la imperfección, Ibn Ezrá utiliza los conceptos de עצם 'sustancia' y תבנית 'forma' o 'estructura'. En contextos similares Ibn Ezrá suele utilizar los términos צורה y עצם. Así, por ejemplo, en su Séfer ha-Ehad, dice Ibn Ezrá que «todo ser es sustancia (עצם) y forma (צורה), pero no es así el Uno», refiriéndose a Dios ${ }^{12}$. En su comentario corto a Éx 3,13 también dice «todo ser está compuesto de sustancia (עצם), (צורה) y dimensiones (גבול). La sustancia es eterna por sí misma y la forma cambia la cosa» ${ }^{13}$. En el Séfer Sahot, explica que «el álef indica la sustancia (עצם) de la cosa, que es el fundamento, como ya he explicado, es la sustancia (עצם) adecuada para recibir la forma (צורה) y entonces se hace existente (נמצט). La forma no existe hasta que hay dos [principios]» ${ }^{14}$.

En su comentario largo a Éx 25,40 Ibn Ezrá habla de la existencia de dos tipos de sustancia, una que es corporal (עצם שיהיה גוף), que sería la materia, y otra que no lo es (עצם שאיננו גוף). Tanto los ángeles como el alma del ser humano poseen el segundo tipo de sustancia. Respecto a la forma (צורה) también habla Ibn Ezrá de dos tipos: «una es eterna y no desaparece, es la forma de los ángeles y la sabiduría que está en el alma humana, también en los cuerpos, como el calor del fuego y la humedad del agua; otra son los accidentes que no son eternos, cambian, vuelven, desaparecen y acaban» ${ }^{15}$.

En relación con esa segunda clase de formas, encontramos un pasaje significativo en su introducción al comentario a Eclesiastés

${ }^{10}$ Com. Éx. pág. 304 y también I. S. Reggio (ed.), Abraham Ibn-Ezra's Commentary to Exodus (Vienna 1926) pág. 200.

11 Agradezco a Shlomo Sela sus sugerencias sobre estas interpretaciones.

12 I. LEvin, Abraham Ibn Ezra. Reader (New York-Tel Aviv 1985, en adelante Reader) pág. 399.

13 Com. Éx. pág. 244.

14 C. DEL VAlle (ed.), Sefer Sahot de Abraham Ibn 'Ezra (Salamanca 1977) págs. 202-203.

${ }_{15}$ Com. Éx. pág. 176 
en el que Ibn Ezrá afirma que «ningún ser puede crear la sustancia, que es la raíz, ni hacerla desaparecer hasta aniquilarla; todas sus obras son simplemente imitaciones, imágenes y accidentes» ${ }^{16}$. En este pasaje Ibn Ezrá contrapone los conceptos de עצם, por una parte, y תמונה, מקרה y מות, por otra.

Basándonos en estas explicaciones, podemos concluir que lo que quiere decir Ibn Ezrá en su introducción del comentario a Job es que el ser humano posee, por una parte, una sustancia no corporal, eterna y perfecta, similar a la de los ángeles y, por otra, una forma que cambia y que es imperfecta. La imperfección del resto de los seres terrenales se debe a que tanto su sustancia como su forma son imperfectas, es decir, carecen de esa sustancia perfecta que posee el ser humano.

En algunas ocasiones Ibn Ezrá parece identificar sustancia (עצם) con materia (חומר) como en el poema que comienza con las palabras ${ }^{17}$ en el que dice:

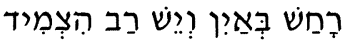

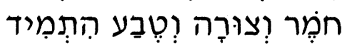

Habló en la inexistencia y reunió una gran existencia, materia y forma y naturaleza eternizó.

Y. Cohen ha señalado la relación de los conceptos עצמר y en el pensamiento de Ibn Ezrá y sus conexiones con la filosofía de Ibn Gabirol ${ }^{18}$.

En varias ocasiones en La fuente de la vida, Ibn Gabirol habla del ser creado como un compuesto de materia y forma; así afirma que lo que hace diferentes las cosas unas de otras es la forma que recibe su correspondiente materia y, por lo tanto, la diversidad de seres depende de la forma, no de la materia ${ }^{19}$. En otro pasaje afirma que

16 Com. Ecl. págs. 7*, 6.

17 I. Levin (ed.), The Religious Poems of Abraham Ibn Ezra (Jerusalem 1975) vol. I págs. 319-321.

18 COHEN págs. 175-178. Una afirmación muy similar a la que aparece en el poema de Ibn Ezrá la podemos encontrar en el Kéter maljut de Ibn Gabirol donde

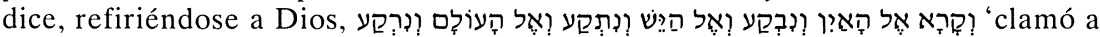
la inexistencia y se hendió, a la existencia y quedó establecida, al mundo y se extendió'; cfr. H. SChiRMann, Ha-širá ha- 'ibrit bi-Sfarad u-be-Provance (Tel Aviv 1954) vol. I pág. 262.

19 Shelomó IBN Gabirol, La fuente de la vida. Trad. del latín por F. DE CASTRO Y FERNÁNDEZ (Barcelona 1978, en adelante Fuente) pág. 51. Véase también H. KREISLER, «The Place of Man in the Hierarchy of Existence in the 
«puesto que nuestro propósito ha sido especular acerca de la materia y de la forma universales, hemos de decir que lo compuesto de materia y forma se divide en dos, uno de los cuales es la sustancia compuesta corpórea, y el otro la sustancia simple espiritual, y que la sustancia corpórea se divide en otros dos, porque una de ellas es la materia corpórea sustinente de la forma de las cualidades, y la otra la materia espiritual, que sostiene la forma corporal» ${ }^{20}$.

¿Por qué comienza Ibn Ezrá su explicación del libro de Job con esa teoría? Después de especificar el origen de la imperfección de los seres humanos, Ibn Ezrá añade la siguiente frase: «esta es la causa de las desgracias que le suceden al alma, al cuerpo, o a ambos, a la riqueza, a los hijos, a las mujeres y a los amigos» ${ }^{21}$. Las desgracias que les suceden a los seres humanos son producto de la propia imperfección que poseen, es algo innato. Por lo tanto, las adversidades que le ocurrieron al justo Job no son un castigo por sus malas acciones, sino la consecuencia de su propia imperfección como ser humano. Ibn Ezrá está utilizando un argumento filosófico para explicar el tema que tantos problemas ha dado a los intérpretes de este libro bíblico: los sufrimientos del hombre que cumple la ley de Dios tienen una justificación filosófica.

Ibn Ezrá vuelve a insistir en dicha idea en su comentario a Job 37,23. En esta ocasión explica que los sufrimientos del ser humano no son producto de las acciones de su corazón sino que son la consecuencia «de la imperfección del que recibe [מחסרון המקבל]». La expresión la utiliza el autor en un contexto similar en su introducción al comentario a Eclesiastés donde explica que «la raíz del mal procede de la imperfección del que recibe [מחסרון המקבל]» 22. En el pensamiento de Ibn Ezrá dicha expresión puede referirse al que recibe la influencia de los astros, que engloba a todos los seres del mundo terrestre, o al que recibe el alma del mundo supe-

Philosophy of Ibn Gabirol and Maimonides», en M. Hallamish (ed.), 'Alei Sefer. Studies in the Literature of Jewish Thought Presented to Rabbi Dr. Alexandre Safran (Ramat Gan-Jerusalem 1990) págs. 95*-107*. Sobre la materia y la forma en los griegos y en el neoplatonismo, véase J. M. DILLON, «Solomon Ibn Gabirol’s Doctrine of Intelligible Matter», en L. E. GoodmAN (ed.), Neoplatonism and Jewish Thought (Albany 1992) págs. 43-59.

${ }^{20}$ Fuente págs. 48-49.

${ }^{21}$ En su comentario a $E c l$ 2,21, Ibn Ezrá cita TB-Mo'ed Catán 28a para apoyar su teoría de que la duración de la vida humana, los hijos y la comida dependen de las decisiones de los astros; Com. Ecl. págs. 25*-26*, 45.

${ }^{22}$ Com. Ecl. págs. 6*, 5. 
rior, que es el ser humano solamente; en ambos casos, se trata de seres que poseen imperfección por naturaleza.

En relación con el origen del mal, son interesantes sus comentarios a propósito de poder y miedo están con Él e impone paz en las alturas (Job 25,2). Explica que «en las alturas no existe la guerra y todo es bueno, el mal está abajo en la tierra», es decir, el mal sólo existe en el mundo inferior, mientras que en el mundo superior sólo existe el bien. En este versículo nuestro autor identifica el dualismo paz / guerra como el bien / el mal.

Son varias las ocasiones en su comentario al libro de $J o b$ en las que Ibn Ezrá trata el asunto del origen del mal en el ser humano, entendiendo en esos casos el concepto de 'mal' no el que sufre el ser humano, sino el que provoca. Así, al comentar Job 5,6 explica

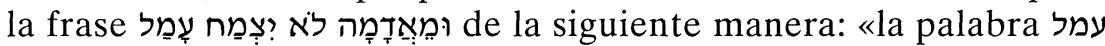
tiene el mismo significado que און cuando van unidas», es decir, que cuando ambas palabras aparecen en el mismo versículo significan 'maldad'. A continuación afirma que «la maldad no brota, sino que la produce el ser humano, como si sólo hubiera nacido para provocar maldad e iniquidad (עמל ואון), similar [al versículo] mira que en la maldad nací (Sal 51,7), porque la naturaleza del ser humano está predispuesta para hacer el mal, lo mismo que el significado de la naturaleza del corazón humano es mala (Gén 8,21)». Esto indica que la maldad es innata en el ser humano, producto de su propia imperfección. En su comentario a Sal 51,7 dice Ibn Ezrá que en el momento de nacer se pone en el corazón de los seres humanos la predisposición hacia el mal. Ibn Ezrá también cita este versículo en su comentario a Job 14,4 donde explica que la expresión ¿quién sacará pureza de lo impuro? significa que el hombre ha sido creado a partir de algo impuro. Nuestro autor se basa en estos versículos bíblicos para afirmar que el mal del ser humano es consecuencia de su propia naturaleza imperfecta.

\section{Alma y CUerpo}

Otra de las ideas filosóficas de Ibn Ezrá que aparecen en su comentario al libro de $J o b$ es la de que el hombre está compuesto de alma y cuerpo. En su comentario a Job 4,19 explica Ibn Ezrá que la expresión los que habitan en casas de barro se aplica a las almas de los seres humanos que son introducidas en los cuerpos. Dice además que los seres superiores, los ángeles, de donde procede el alma humana, no tienen materia corporal (גשם שהוא גוף). El 
alma humana está prisionera en el cuerpo y desea liberarse y retornar al lugar del que procede, el mundo celestial. Basándose en este mismo concepto, Ibn Ezrá interpreta mi alma preferiría ser estrangulada, la muerte más que mis huesos $(J o b \quad 7,15)$ de la siguiente manera: «mi alma prefiere la muerte más que habitar en mis huesos, porque el cuerpo es como la casa del alma y la base del cuerpo son los huesos, que son como los cimientos y las columnas». También en su comentario a Job 1,21 explica que los huesos proceden de la tierra y son los que sostienen el cuerpo ${ }^{23}$. En los casos mencionados nuestro autor está utilizando los significados metafóricos del texto bíblico para encontrar un fundamento de sus teorías filosóficas. Lo que resulta interesante de estas observaciones es cómo Ibn Ezrá es capaz de encontrar en el texto bíblico metáforas que le permiten integrar ideas de la filosofía griega en el pensamiento judío.

En su comentario a $J o b$ 14,15 encuentra otra metáfora para apoyar su teoría de que el alma está encerrada en el cuerpo. El versículo dice, refiriéndose a Dios, me llamarias y yo te respondería, anhelas la obra de tus manos. Ibn Ezrá lo explica de la siguiente manera: «cuando me quites la vida no tendré fuerzas para negarme. La palabra anhelas significa que quieres ver la obra de tus manos, que es el alma». En el contexto de muerte en el que está el versículo podemos deducir que Ibn Ezrá aquí explica el versículo como un deseo divino de que el alma vuelva a Dios después de la muerte, pero añade una condición, citando porque el espíritu ante Mi debe ser humilde (Is 57,16), que es la de que el alma se presente ante Dios con humildad ${ }^{24}$. A propósito de la expresión su espíritu y su alma hacia Él retiraría $(J o b 34,14)$ alude Ibn Ezrá a la teoría del retorno del alma humana al lugar del que procede. En su comentario a Job 34,15 explica Ibn Ezrá que la expresión toda carne expirará a una y el hombre al polvo volverá se refiere al

$23 \mathrm{Al}$ interpretar Gén 3,19 dice que los huesos han sido creados a partir del polvo de la tierra, son los fundamentos del cuerpo y son similares a la estructura de una casa, L. PriJs (ed.), Abraham Ibn Ezra's Commentary on Genesis Ch. 1-3. Creation and Paradise (London 1990) pág. 139.

${ }^{24}$ En la introducción a su comentario a Eclesiastés, Ibn Ezrá explica que el alma está prisionera en el cuerpo del ser humano, pero tiene un deseo irrefrenable de volver al lugar que le corresponde, que es el mundo divino. Para permitir que el alma cumpla su objetivo, Ibn Ezrá afirma que la labor del sabio es la de conseguir la perfección del alma mediante el conocimiento de Dios; Com. Ecl. págs. $5 *-7 *, 3-7$. 
cuerpo, a la parte visible del ser humano. Con esto quiere dar a entender que existe otra parte del ser humano que no es visible, que es el alma, la cual no muere como el cuerpo. También a propósito de cuando Dios quita la vida (Job 27,8) Ibn Ezrá especifica que se trata de la vida del cuerpo sólamente. En estos casos la teoría filosófica de la división del ser humano en estos dos elementos le sirve para concretar y completar el significado del texto bíblico.

La idea de que el hombre es un compuesto de alma y cuerpo y que aquella asciende al cielo después de la muerte aparece en muchos filósofos neoplatónicos medievales, como Ibn Gabirol e Ibn Paquda ${ }^{25}$.

\section{EL CONOCIMIENTO HUMANO}

Otro de los asuntos filosóficos que trata Ibn Ezrá en su comentario a $J o b$ es el problema del conocimiento humano ${ }^{26}$. En su comentario a ¿no se les arrancó su provecho? Mueren y no con sabiduría (Job 4,21) Ibn Ezrá da a entender que el versículo alude a los que se ocupan de acumular riquezas, que mueren sin sabiduría, porque únicamente «fueron sabios para reunir riquezas». Y añade «este versículo demuestra que el hombre sólo ha sido creado para aprender la Sabiduría». Distingue, pues, este autor entre

\footnotetext{
${ }^{25}$ Según la explicación alegórica de Ibn Gabirol del versículo Gén 2,8, el alma es una sustancia espiritual, separable del cuerpo, que goza de la felicidad gracias al conocimiento del mundo superior; cfr. C. SIRAT, A History of Jewish Philosophy in the Middle Ages (Cambridge 1985) págs. 79-80. Esta es una de las ideas más importantes del pensamiento de Ibn Paquda, quien afirma que «el intelecto es una entidad espiritual que procede del mundo superior y que es un extraño en el mundo de los cuerpos materiales» (SIRAT History pág. 82). Sobre el desarrollo de esta teoría en los filósofos judíos neoplatónicos; cfr. SIRAT History págs. 85, 87-88, $101,106-109$ y $134-136$.

${ }_{26}$ Se trata de uno de los grandes temas que preocuparon a los filósofos griegos y medievales. La cuestión que se planteaba era cómo era posible que el ser humano pudiera llegar a comprender una realidad tan compleja y variada como la de los diversos seres existentes en este mundo. Platón estableció que para adquirir el verdadero conocimiento era necesario apartar las características peculiares de los seres individuales y buscar las características comunes que permiten agruparlos en clases. Aristóteles también defendía que adquirir conocimiento significa encontrar las características universales de las cosas, pero, a diferencia de Platón, Aristóteles defendía que para eso había que empezar por conocer a los seres individuales; cfr. D. C. LINDBERG, The Beginnings of Western Science (ChicagoLondon 1992) págs. 34-39 y 50-51.
} 
dos tipos de sabiduría: la que se utiliza para reunir riqueza y la Sabiduría Suprema que lleva a la perfección del alma; esta última es la que produce provecho. Esta distinción es fundamental en su comentario a Eclesiastés porque se basa en ella para argumentar que las observaciones que existen en el texto bíblico sobre lo inútil de la sabiduría se refieren solamente a aquella que se utiliza para obtener beneficios materiales, pero no es así el caso de la Sabiduría Suprema que consiste en el conocimiento de Dios y que lleva a la perfección del alma humana ${ }^{27}$. En el caso del comentario a $J o b 4,21$, Ibn Ezrá simplemente alude a esta idea pero no la desarrolla.

El comentario de Ibn Ezrá a Job 40,6-8 hace una referencia a que sólo Dios es capaz de conocer tanto lo general (כלל) como lo particular (פרט) ${ }^{28}$. El hombre, por lo tanto, no es capaz de llegar a ese conocimiento que es exclusivo de Dios porque su entendimiento es limitado. De esta manera justifica Ibn Ezrá que si resulta difícil entender la actuación de Dios con Job se debe a la limitación del entendimiento humano. En sus explicaciones del discurso de Dios en los capítulos 40 y 41, Ibn Ezrá quiere demostrar que las palabras que este dirige a Job tienen como objetivo mostrar lo inútil que resulta tratar de entender la naturaleza de Dios y todas sus obras ${ }^{29}$. En este caso Ibn Ezrá utiliza la teoría filosófica que distingue entre el conocimiento de lo general y lo particular para dar argumento filosófico a su interpretación del texto bíblico.

En el capítulo 28 del libro de $J o b$ se dice que sólo Dios conoce el camino de la Sabiduría y sabe dónde está su lugar; después el texto bíblico continúa Él contempla los límites de la tierra y ve lo que hay bajo los cielos, marcando el peso al viento y señalando la medida de las aguas. A propósito de este pasaje Ibn Ezrá explica que «el hombre no puede conocer estos sentidos, sólo el Creador, que hizo los cuatro elementos, tierra, cielos, aire y agua, y son mencionados en los dos versículos». Ibn Ezrá encuentra aquí una

27 Véanse, por ejemplo, sus comentarios a $E c l$ 1,3, 2,15.26 y $3,12$.

28 En su comentario a $E c l 1,8$, Ibn Ezrá explica que «el ojo no puede dominar los particulares, ni puede el oído escucharlos todos ellos, porque son infinitos e inumerables para los hombres; sólamente el Creador conoce lo general y lo particular, porque todo ello es obra de sus manos»; Com. Ecl. págs. 14*, 21.

${ }_{29}$ Ibn Gabirol señalaba que es imposible conocer la esencia de Dios, pero sí podemos conocer su existencia a través de las acciones divinas en este mundo; cfr. SIRAT History pág. 73. 
referencia a la teoría de los cuatro elementos de los que están formados los seres terrestres: tierra, fuego, aire y agua ${ }^{30}$.

En el primer capítulo de su Séfer Yesod morá’, Ibn Ezrá cita los versículos bíblicos en los que aparecen mencionados los cuatro elementos y llama la atención que en todos ellos los «cielos» aparece como una alegoría del fuego ${ }^{31}$. En su comentario a Sal 148,2 explica esta identificación al decir que en el mundo superior se encuentran los «cielos de los cielos» que constituyen la «esfera del fuego» y que está relacionada con la esfera de la luna ${ }^{32}$.

La limitación del conocimiento humano también existe en el mundo material de los particulares, porque no se pueden conocer los límites de los cuatro elementos de los que está formada la materia.

En su comentario a Ecl 1,4 Ibn Ezrá explica que las palabras 'tierra', 'sol', 'viento' y 'mar' mencionadas en los vss. 4-7 de ese libro bíblico son una alegoría de los cuatro elementos de los que está compuesta la materia. La razón de que aparezcan estos elementos mencionados aquí es, según Ibn Ezrá, para demostrar que el conocimiento del ser humano es limitado porque no puede llegar a conocer los inumerables seres que proceden de estos cuatro elementos. Tanto en el caso de Job como en el del Eclesiastés, Ibn Ezrá encuentra una conexión entre el significado alegórico del texto bíblico y las teorías filosóficas de su tiempo.

En el comentario a Job 38,36, Ibn Ezrá establece la relación que existe entre el conocimiento y el espíritu: los pensamientos son como formas grabadas (צורות חקוקות) en el corazón ${ }^{33}$, como piedras esculpidas. Para demostrar dicha idea, nuestro autor utiliza

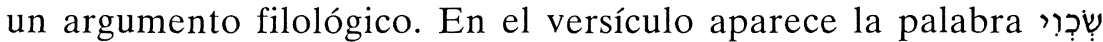
interpretada tradicionalmente con el significado de 'gallo' ${ }^{34}$. Se-

${ }^{30}$ Sobre esta idea en el pensamiento de Ibn Ezrá, véase COHEN págs. 73-76. También Saadiá Gaón explicaba a propósito de Job 28,24-25 la teoría de los cuatro elementos de los que están formados los seres; D. KAFIAH (ed.), 'Iyob 'im targum u-ferús ha-Gaón Rabbenu Se'adiá (Jerusalem 1973) pág. 146.

${ }_{31}$ Los versículos son Ecl 1,3-7, Gén 1,1-2, Is 40,12-13, Sal 104,2-5 y 33,6-8, y Prov 30,4. Cfr. Reader págs. 318-319.

${ }^{32}$ SELA Astrology págs. 94-97 señala la relación entre las teorías cosmológicas de Ibn Ezrá sobre la composición del Universo y la filosofía aristotélica.

33 Sede de la inteligencia según el pensamiento judío.

${ }^{34}$ F. Brown - S. R. Driver - Ch. A. Briggs, A Hebrew and English Lexicon of the Old Testament (Oxford 1968) s.v.; Sagrada Biblia, eds. F. CANTERA BURGOS y M. Iglesias GonZÁlez (Madrid 1979) pág. 716; y N. H. TuR-SinAI, The Book of Job: A New Commentary (Jerusalem 1967) págs. 533-535. 
gún Ibn Ezrá significa 'corazón' y para justificar esta interpretación cita dos versículos: Sal 73,7 y Lev 26,1. En el primer caso nos

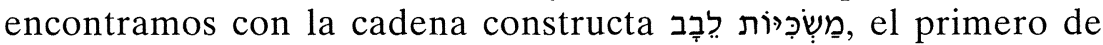
cuyos términos es de la raíz שכְְִִׁ! En su comentario a dicho versículo Ibn Ezrá cita la opinión de Moisés ha-Kohén ibn Chiquitilla que lo interpreta como 'pensamientos del corazón' considerando que la palabra שכוי es un apelativo del corazón. En

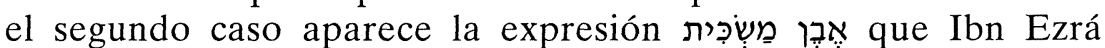
interpreta como 'piedra de formas esculpidas' y explica que estas formas se refieren a los pensamientos. Aparte de utilizar la teoría de Ibn Chiquitilla, Ibn Ezrá seguramente conoció la interpretación de Ibn Yanah a Job 38,36. En su Séfer ha-Šrašim explica

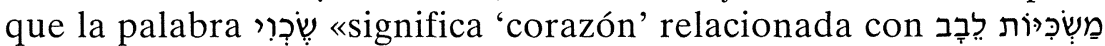
( Sal 73,3) porque el pensamiento está en él y además se usa en lugar de la palabra נפש ['espíritu'], como suele suceder en muchas ocasiones en hebreo» ${ }^{35}$. Ibn Ezrá pues sigue esta tradición filológica de los autores españoles para justificar su pensamiento filosófico.

La misma idea es empleada por Ibn Ezrá en la introducción a su comentario a Eclesiastés, donde afirma que cuando el espíritu del hombre se purifica está preparado para conocer las palabras verdaderas que «se grabarán en él y no se borrarán al separarse de su cuerpo». Esto quiere decir que, en el momento de la muerte, el alma del sabio estará preparada para conocer los significados que a lo largo de la vida se han ido grabando en ella. Muy significativo también es un pasaje del capítulo diez de su Séfer Yesod morá donde afirma que «el alma humana, tal como fue otorgada por Dios, es como una tabla en la que se puede escribir y lo que en ella se escribe es escritura divina» ${ }^{36}$. Se trata de la sabiduría que el ser humano adquiere para perfeccionar su alma y acercarla a Dios.

\section{CONCLUSIÓN}

En su comentario al libro de Job, Abraham ibn Ezrá utiliza las teorías filosóficas del pensamiento neoplatónico de su tiempo para justificar que las desgracias que le suceden al justo Job son conse-

35 W. BACHER (ed.), Sepher Haschoraschim: Wurzelwörterbuch der hebräischen Sprache von Abulwalîd Merwân Ibn Ganah (R. Jona) (Berlin 1896) pág. 511.

${ }^{36}$ Reader pág. 337. 
cuencia de la propia imperfección del ser humano. Para ello explica el origen de la imperfección en los distintos seres que ocupan tanto el mundo inferior como el mundo superior de los ángeles y los astros distinguiendo en ellos dos elementos básicos de su constitución: la sustancia y la forma. En otros pasajes de este texto bíblico, Ibn Ezrá utiliza otras teorías filosóficas propias de su época como la división de los seres humanos en alma y cuerpo, la dificultad para conocer tanto los seres particulares como los principios generales, la composición de la materia en los cuatro elementos y la relación entre el conocimiento humano y el espíritu. Basándose en esas ideas, Ibn Ezrá es capaz de encontrar significados alegóricos y metafóricos en el texto bíblico desconocidos hasta entonces y en ellos demuestra su verdadera originalidad.

\section{RESUMEN}

Este artículo es un análisis de las teorías filosóficas utilizadas por Abraham ibn Ezrá en su comentario a $J o b$ para explicar el significado de algunos versículos bíblicos y dar razones filosóficas del problema central de este libro: el justo que sufre desgracias sin razón aparente. En él se analiza cómo este autor utiliza las teorías filosóficas de su tiempo sobre el origen del mal, la dualidad almacuerpo y el problema de la limitación del conocimiento humano para explicar algunos significados metafóricos del texto bíblico.

\section{SUMMARY}

This article is an analysis of Abraham Ibn Ezra's philosophical theories in his commentary on $J o b$ and how he uses them to interpret some biblical verses and to give a rational justification of the main question of this biblical book, namely, the sufferings of the rigtheous. In this article, I analyze how Ibn Ezra uses philosophical theories of his time, such as the origin of evil, the soul-body duality, and the problem of the limitation of the human knowledge, to explain some metaphors in the biblical text. 